\title{
Educational Entrepreneurship (EE): Delineating and Highlighting Its Domain, Importance and Feasibility in Uganda's Context
}

\author{
Genza Gyaviira Musoke*, Musisi Badru \\ School of Education, College of Education \& External Studies, Makerere University, Uganda
}

\begin{abstract}
Article Info
Article history:

Received Sep 2, 2017

Revised Nov 19, 2017

Accepted Jan 2, 2018

Keywords:

Educational entrepreneurship Educational management Intrapreneurship School leadership

ABSTRACT

Although government financial support for education is dwindling in many African countries, not many educational institutions have succeeded in devising internal mechanisms to enable them to continuously deliver quality education in quantity. Might the application of certain entrepreneurial strategies in educational management perhaps help to make a difference? What is educational entrepreneurship (EE)? How feasible is EE in a developing world education landscape like that of Uganda? Which challenges must EE surmount before it can envisage success? Using literature review methodology, this study attempted to find answers to such questions. Its aim was to delineate the EE domain and to highlight both its importance and feasibility in Uganda's context. The study makes two key revelations; first, indeed EE is clouded in conceptual mishmash, hence need for more scholarly attention; second, however salvaging EE can be to struggling educational institutions, it is not without serious challenges - even apparent contradictions - hence preference for a "moderate risk" approach to entrepreneurship within educational institutions.
\end{abstract}

Copyright $@ 2018$ Institute of Advanced Engineering and Science. All rights reserved.

\section{Corresponding Author:}

Genza Gyaviira Musoke;

School of Education, College of Education \& External Studies,

Makerere University, Uganda.

Email: musokegenza@gmail.com

\section{INTRODUCTION}

Educational Entrepreneurship (EE)-entrepreneurship carried out in education institutions-has received growing scholarly attention in recent years, particularly in the Western World [1]. This has been propagated by dwindling public and donor financing of education [2], on the one hand; and widespead failure by most educational institutions to generate their own funds from within [3], on the other. Nevertheless, the concept of "EE" (Educational Entrepreneurship) still eludes the comprehension of many. Besides, the feasibility of EE in a third world education landscape, like that of Uganda, also appears to raise more questions than answers. Delineating EE might therefore help to open the EE concept to both more scholarly attention (by researchers) and more empirical application (by practitioners-both educational managers and the wider business community). Hence the current study, which reviews existing EE literature with the purpose of delineating the EE domain and highlighting both its importance and feasibility in the Ugandan context. More specifically, the paper's objectives are four; namely, to: a) Shed more light on the meaning of the term Educational Entrepreneurship (EE), b) Delineate the scope of the EE domain, c) Highlight the potential significance of EE in the management of education in Uganda, d) Determine the feasibility of EE in the Ugandan context. 


\section{STUDY'S METHODOLOGICAL UNDERPINNINGS}

This study pursued a narrative literature review design [4]-[5], whereby peer-reviewed articles were used as the main source of information and data. This implies that peer-reviewed literature was the parent population to which the researchers went for sampling (of relevant articles), data collection (from each chosen article), analysis (of opinions collected from various articles) and ethical applications (mainly issues of academic honesty vis-à-vis plagiarism) [6], [5]. Following its narrative design approach, the study relied on interpretivism as its epistemological stance. Consequently, it is thematic analysis that was used for both data analysis and synthesis. Findings were eventually organised and presented around four themes [7] emanating from the study's four specific objectives.

To locate peer-reviewed sources that are relevant to EE, the study mainly relied on the Google Scholar search engine; using "educational entrepreneurship", "entrepreneurship in education" and "educational entrepreneurs" as its key search terms [4]. The terms sometimes led to journal and non-journal (text book) sources on such related themes as "corporate entrepreneurship", "intrapreneurship" and/or "entrepreneurship". These were also explored and included/excluded depending on their relevancy to the study objectives. In any case, the study's strict adoption of the above three key search words, as well as its primary reliance on the Google search engine, might have limited the kind of journal articles that became available. However, delimitation was achieved by following up key references that the reviewed articles had in their reference lists-a kind of "go backwards" approach [6]-which also helped to locate other sources that the study might otherwise have missed.

In the end, the study included only peer-reviewed articles and other sources that were available in the English language and had been published between 2000 and 2017. For a study that is largely "conceptual" in nature (clarifying the educational entrepreneurship domain), using articles stretching back to the year 2000 was considered valid. This study was carried out between 2014 and 2017.

\section{THE CONCEPT OF EDUCATIONAL ENTREPRENEURSHIP (EE)}

This study construes EE as the routine application of entrepreneurial competences to addressing society's educational problems. This definition, however, is rather tentative because it falls short of unpacking the two complex concepts of "education" and "entrepreneurship". The paper attempts to clarify these two concepts first before fine tuning the definition of EE.

Among the many meanings of the term "education" are the liberal ones, which take the term to mean socialisation of the young-the process of teaching the young to live as useful and acceptable members of society [8]-[9]. This kind of education may even take place under informal settings such as at home or church/mosque [10]. However, more formal (technical) definitions of the term education link it with development of cognitive states of a person. This involves knowledge and understanding in depth and breadth, suggesting also that what is acquired is desirable [10], [8]. In this regard, [11] define education as experiences, both planned and unplanned, that take place within a setting specifically designed for learning-a place called school. In a formal sense, therefore, education is the "process which intentionally transmits what is considered by society as valuable, in an intelligent and voluntary manner" [12]. Against this backdrop, the current study adopted the latter definition i.e. one of "formal education" or "schooling" at all levels including early child, primary, secondary and higher education.

The second concept is "entrepreneurship". According to [13], "entrepreneurship is when you act upon opportunities and ideas and transform them into value for others. The value that is created may be financial, cultural, or social" (p. 117). However, [14] offer a more precise definition of entrepreneurship as the "process of creating something new with value by devoting the necessary time and effort; assuming the accompanying financial, psychological and social risks; and receiving the resulting rewards of monetary and personal satisfaction and independence" (p. 24). The current study also takes entrepreneurship to be the process of creating (educational) value by both identifying given opportunities and passionately going forth to pursue them for personal and social gain. Thus, entrepreneurship is not just about creating business enterprises. It is about bringing a certain set of skills, intellectual attributes and innovative approaches to bear on solving problems in the public, for-profit and/or not-for-profit sectors [13].

In solving such problems, entrepreneurship may take any one of the two different "modes of exploitation" [15]: "Independent entrepreneurship" (opportunity pursuit by starting an independent business entity) and "organisational entrepreneurship" (pursuit of a business opportunity within an already existing organisation). The latter mode is technically referred to as "corporate entrepreneurship" [16] or "intrapreneurship"-if a business initiative is spearheaded by lower-level individual employees [17]. Whatever the mode of exploitation, entrepreneurship is characterised by several elements (dimensions), three of which are taken to be more important [15]. These are innovativeness (a predisposition to engage in creativity and experimentation of new ways of doing things); pro-activeness (an active opportunity-seeking 
and forward-looking perspective-an attempt to lead rather than follow); and risk-taking (since considerable resources must be invested before return on them is known) [18]-[19].

The first objective of the current study being to highlight the meaning of the term EE, it is at this point that the hitherto illuminated meanings of the two concepts of education and entrepreneurship are combined into "EE". Available literature shows that to-date, a few scholarly attempts have been made to conceptualize the notion of entrepreneurship in an education management context [18]. The few attempts include [20], [13], [21], [22], [1]. It is with the help of these studies that the current study attempted to shed more light on the meaning of the term EE, particularly in a Ugandan context.

According to [13], EE "is about applying the skills and attitudes inherent in entrepreneurial thinking and the entrepreneurial process to achieve innovative and sustainable impact and reforms with respect to the social mission of education" (p. 117). In this regard, the idea of social mission (social entrepreneurship) is a necessary condition for a valid conceptualisation of EE. However, by defining EE in terms of "entrepreneurial" thinking, [13] definition presupposes that the meaning of the term entrepreneurship is already clear to readers. In other words, the definition focuses more on the description of EE than it does on its meaning. Secondly, [13] definition is rather wordy.

The second definition is by [20]. Here EE is defined as the instigation of certain changes in the public education system-changes that will disrupt, transform, or radically alter the way education is provided [20]. According to this definition, not every change qualifies to be called EE; it is only "radical transformation" changes that qualify.

Moreover, the idea of disruption, transformation and radical alteration of the way education is provided is consistent with Schumpeter's notion of "creative destruction", which alludes to a relentless innovation mechanism by which new education processes replace outdated ones. It is also worth noting that, according to this definition, the ultimate goal of EE is improvement in the provision of education and not just monetary gain.

In keeping with the above view of "radical transformation", are studies by [23], [21]. [23] describes EE as "bold interventions" to improving educational equity and quality; [21] takes "education entrepreneurs" as "a rare breed of innovators whose characteristics and activities may lead to the transformation-not merely the slight improvement-of the public education system [sic]" (p. 2). Thus, EE is taken to be radical, bold and transformational. However, how "radical" can one be at the beginning? Where would this "radical approach" put most entrepreneurs' philosophy of "moderate risk" to investment? More so, since society seems to expect educational institutions to play more of conservative than revolutionary roles, how will a radical EE fair in a non-radical educational environment? These questions point to constraints in [23], [21] EE conceptualisations, as will be discussed later.

Another study that has attempted to define EE is [22], who view it as the strategic focus of educational institutions "on creating short and long-term opportunities for learning that will make a significant difference for individuals and their societies" (p. 4). The authors hasten to add that while financial returns are a sufficient ingredient that ensures the quality of education in EE, they (financial returns) do not necessarily constitute the primary concern of EE. EE's primary concern is "building human and social capacity to lead responsible, constructive educational initiatives" [22]. Finance becomes important mainly in view of sustainability by ensuring that educational programs initiated are of a consistently high standard. Thus, EE does not simply aim at the provision of education service; rather, it aims at continuous adaptation of education systems to society's changing needs in innovative, proactive and audacious ways that result in provision of quality education in quantity and in a manner that is sustainable.

The last, and most recent, definition is by [1], who view EE as the process of identifying an educational problem, followed by the spotting of an opportunity to solve it innovatively-in a manner that adds value for both the immediate surroundings (micro context) and the broader education system (macro level). Just like the previous definitions, this definition implies that $\mathrm{EE}$ is about devising smart ways of solving educational problems.

Both in keeping with the foregoing definitions and in correcting their excesses, the current article defines EE as the innovative application of smart strategies to the management of education institutions in a way that can result in the reorganisation of a country's education system to suit society's changing needs in a sustainable manner. This definition implies that entrepreneurial education managers are those who relentlessly scan their environments to identify society's changing educational needs. Then they audaciouslybut wisely-devise innovative strategies to address current and (emerging) future educational challenges and needs in proactive rather than reactive ways. Furthermore, entrepreneurial educational managers adapt strategies that are capable of transforming an entire educational landscape-even in radical ways.

Thus, EE transcends monetary rewards (financial motives) to enhancement of teaching-learning processes (social mission) [20]. As [13] put it, mere creation of a viable enterprise in the education marketplace does not necessarily qualify a venture as education entrepreneurship. EE is about applying skills 
and attitudes inherent in entrepreneurial thinking in the realisation of innovative and sustainable impact reforms to the social mission of education [13]. Propensity to (educational) innovation is therefore a strong measure of EE, particularly innovation that promises better and more quality in education service delivery [23]. Thus, with EE, entrepreneurship features are applied in school organisations essentially to enhance the success of schools in providing effective teaching and learning [24], and not just to make money.

Yemini et al. [18] qualifies the innovations carried out as those related to school practices and standards in areas such as pedagogy (instructional strategies e.g. IT use); school organisational practices and structural designs that do not directly affect classroom techniques (e.g. adaption of a matrix management structure); and social concerns like creating arrangements to solve social problems (such as pupil absenteeism and teenage pregrancy). Other studies focus on applying innovative practices to solving educational problems, which, according to [25], concern four issues, namely: education distribution (kind of individuals to give education); curricula (skill, knowledge, attitude and value types to promote); pedagogy (how to go about teaching and learning); and resource mobilisation (which financial, human and other resources to use, and how to raise them).

Lavaroni and Leisey [26] recently coined a term "edupreneurship" in reference to entrepreneurship within the realm of education (EE). Accordingly, they define an "edupreneur" as: "A person within the public schools who takes hands on responsibility in creating and developing a program, product, service, and/or technology for the enhancement of learning consistent with the stated goals of and supported by that organisation" [26]. However, given the growing importance of the private sector on the educational landscape at all levels of education, it is not clear why Lavaroni and Leisey confine the definition of edupreneurship to persons within public schools. Apparently, Uganda's competitive education market seems to be promoting entrepreneurial practice more in private than in public education institutions.

\section{ENTREPRENEURIAL COMPETENCES (ECs)}

Educators who exhibit the qualities in the current study's EE definition are said to possess "entrepreneurial competences" (ECs). This is an attendant concept that deserves clarification. According to [27], the term "competency" refers to skills, talent, or traits deemed adequate for performance of a given task. Competences issue from an integration of knowledge, skills and attitudes that enable one to perform adequately in a given field [28]-[28]. Therefore ECs are a set of generic (transversal) skills, knowledge and attitudes, which are key in "turning ideas into action" [13] and, thus, are characteristic of successful entrepreneurs.

Salient examples of discrete ECs that are key in EE are initiative, competitiveness, risk-taking and an ability to prioritise [13]. Comparing these with the three dimensions of an entrepreneurial orientation, risktaking clearly resurfaces. However, the other two dimensions are also implied. Innovativeness goes hand in hand with taking initiative, and competitiveness presupposes pro-activeness. [30] Study conceptualises these (and other) discrete ECs into four generic areas, namely: strategic thinking and visioning, team building, communication and negotiation skills, and financial resource mobilization and optimisation. Available research further indicates that there are two sources of ECs (whether discrete or generic); namely, early home background (personality and self-image) and education (or training) later (acquisition of further skills, knowledge, experience) [30].

The current study contends that by borrowing a leaf from the corporate world and hence by exercising ECs in their routine operations, educational managers will be able to provide sustainable solutions to the tricky educational challenges before them. The study therefore seeks to draw key stakeholders' attention to EE as the way to transform tomorrow's educational management. Indeed ECs are closely linked with leadership and management competences: management competences are more about what managers should be able to do (POSDCORB-Plan, Organise, Staff, Direct, Co-ordinate, Report \& Budget). Leadership and entrepreneurial competences are more about how people behave in carrying out those management and/or other functions [30]. Leadership and ECs are developed when individuals succeed in learning to behave in certain ways - with initiative, proactiveness etc.

This study therefore contends that EE is a type (subset) of educational leadership. Just as educational management without (general) leadership is null and void, educational leadership without an entrepreneurial stance (proactive, risk-taking, competitive, strategic planning) cannot issue in educational excellence (sustainably providing answers to educational problems). Otherwise, as [18] posit, entrepreneurship is one feature of extraordinary leaders whose innovations or solutions to pressing problems bring about transformative benefits to education management. Also "School reform" is hereby construed to be a general term that describes attempts to change dramatically some of the operational premises and practices of both individual schools and entire educational systems [23]. 
In keeping with the fundamentals of ECs, the current study proposes the following model of an entrepreneurial school system; the model is adopted from [21] as RESPO-Responsive to changes in the needs of students, families and communities; Espouses meritocracy as "the fastest learner wins"; Studentoriented-addressing the unique learning needs of different learners; Open to constant learning since operational environments are dynamic and keep evolving; Performance-driven-is effective without forgetting efficiency ("efficiently effective").

\section{DELINEATING THE DOMAIN OF EE}

After examining EE and the competences that characterise it, the paper turns to the domain of EE by answering the following questions: How can one tell that one has crossed the boundary of EE to mainstream business entrepreneurship (BE) or other territories? What are the different shades of EE? Is EE largely a pedagogic move-in view of enhancing teaching and learning-or is it a for-profit strategy-in view of economic gain?

Prominent scholars in EE contend that, in a strict sense, EE bears a social mission connotation [13], [21], [23]. This means that EE basically aims at creating both more and better opportunities for teaching and learning with improved equity and quality being at its core [23], [22]. However [22], acknowledge also that (because of the importance of sustainability) financial return sufficient enough to ensure quality is an important ingredient of EE. It is necessary to ensure that programs initiated are both enduring and of a consistently high standard. Thus, although in itself EE is not essentially a profit move, it should be profitable (at least in the long run) to ensure program continuity, quality and even quantity (escalation). To locate more vividly where EE lies in relation to other forms of entrepreneurship and to highlight its different faces, the current article adopts [20]'s model depicted in Figure 1.

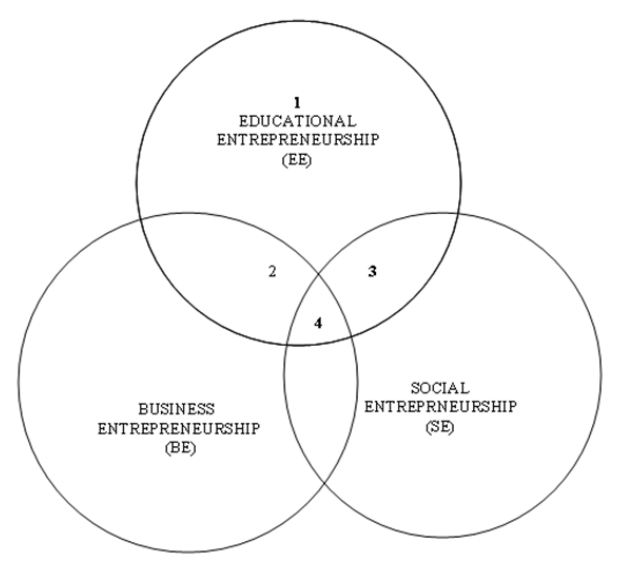

Figure 1. Different entrepreneurship domains and forms of EE

Figure 1 shows that in general entrepreneurship consists of three main domains, namely; business entrepreneurship (BE), social entrepreneurship (SE), and EE. BE is associated with ordinary profit-making small, medium and large scale firms (economic value). Some are business ventures in the education sector such as for-profit schools and provision of education support services such as transport, catering, uniform, and entertainment. If such a venture's bottom-line is economic gain, then it is excluded from the domain of EE.

Then SE (Social Entrepreneurship) is about innovative ventures bent on making communities better places to live in by, for example, developing affordable safe motherhood interventions (social value). In the education context, SE focuses on areas unattended to by the mainstream education system such as developing catch-up programs for slow-learning children. In this regard, SE intersects with EE [20].

The third domain is EE, which is about smart school interventions in view of better teaching and learning (educational value). Within an already existing educational institution, EE is referred to as educational intrapreneurship or corporate entrepreneurship [15]-[16]. In Higher Education, EE is often termed "academic entrepreneurship", which focuses on running consultancies, research centres, copyrights, patents and science parks. It is however important to note that the success of institution-based EE has much 
to do with both the leadership style(s) of the institution's administrators and with their propensity to innovation and change [23].

Note should also be taken of the fact that the three entrepreneurship domains are not mutually exclusive. Innovative interventions that cut across two or even three of the domains do exist. This article is however concerned only with EE types, some of which cut across other domains. According to [20], the EE domain consists of four forms/types code-named 1, 2, 3 and 4 in Figure 1.

The first form consists of entrepreneurial activities and/or ventures that exclusively belong to the domain of EE. Here the activities are both internally generated and institution-based (corporate entrepreneurship) such as school-based remedial classes or teacher retooling programs. The second form consists of profit-oriented supplemental businesses in the education sector. These are initiated either by ordinary business organisations or by educational institutions [20]. A business enterprise may run chains of transport or catering services to support schools in a given locality at a given fee. Similarly, it may publish curriculum materials or provide lab and ICT equipment to be paid for by schools [13]. Such a business may even be a bank providing venture capital for education services. On the other hand, a school may get into agri-business to subsidise its spending on food. Either way it is EE-of the second form.

The third consists of socio-educational ventures that focus on developing new answers to current social and/or ecological challenges in/through schools for the enhancement of social values [13]. Such ventures are initiated either by educational institutions or by community advocacy groups [20]. Whereas the former may initiate open literacy campaigns for the masses, the latter may launch a program for providing school-going children with subsidised mid-day meals, for example.

Lastly, and less common, are entrepreneurial activities that simultaneously cut across the three domains (EE, BE, SE) [20]. For example, a profitable business intervention may be devised in support of an educational initiative for socially disadvantaged families.

Corresponding research paradigms have also been proposed for each of the different forms of EE [20]. Whereas institution-based initiatives (Form 1) may better be studied using corporate entrepreneurship paradigms; ventures with a SE orientation may be studied using structuration theory, social capital, and/or social movements theories. For externally generated EE with a strong business orientation, one may employ paradigms existing in mainstream entrepreneurship literature poised on behavioural, managerial, economic and development perspectives.

\section{IMPORTANCE AND JUSTIFICATION OF EE}

There are scholars, who opine that an adoption of entrepreneurial behaviour in education that can result in both higher financial returns (profit) and more/better teaching and learning is practically impossible [23]. They believe that EE can easily end up serving the business (profit) motive at the expense of the pedagogical one. How then can one justify entrepreneurship in education?

Scholars, who are optimistic about the potential contribution of EE in enhancing quality education in quantity are many [30], [18], [26], [20], [21]. They contend that EE inspires educational administrators not only to comply with institutional demands (such as better grades), but also to take a proactive role in advancing initiatives that reflect the changing needs of their schools [18]. These views imply that by the very nature of the demands of their work, educational administrators should be entrepreneurs.

Secondly, available research indicates that education could gain from entrepreneurial leadership in such ways as confronting competition, mobilising resources, and pursuing a corporate approach to school management [30]. However, the irony is that, to-date, no single university in Uganda offers formal EE training to current or future leaders of education institutions. Indeed available studies reveal that many educational professionals lack entrepreneurship knowledge and competencies regardless of their considerable interest in the field of entrepreneurship [30]. The limited exposure university teacher trainees get in economics of education is too inadequate to equip them with key entrepreneurial competences such as opportunity identification, market assessment, value creation, and product positioning in education. Yet EE is crucial if educational managers are to think and act beyond current rules (policies) and resources. It could enable them to create new educational organisations to execute new visions [21]. In this respect, EE, both in principle and in practice, is needed for the development of educators who are able to cope and lead in a rapidly changing environment [22].

Looking more closely at the Ugandan context, public dissatisfaction with the quality of teaching and learning in schools is palpable, especially in public schools. This is demonstrated by the reality of semiilliterate school completers and unemployable higher education graduates [31]. The growing stakeholder demand for accountability and quality amidst dwindling public resources for education complicates an already complex situation. Today financial resources no longer originate only from government and parents, but also from private sector funds and even industry partnerships [22]. Such changes demand entrepreneurial 
educational leadership and management [30]. In such a setting, the role of networking in enhancing schools cannot be overstated. Indeed educational networking is more important today than ever before in an era where access to information is a primary factor in determining the success or failure of educational institutions. Also forming strategic alliances with other institutions-both educational and non-educational-is a critical success factor today [22].

In addition, economic liberalisation policies playing out in Uganda today have resulted into unprecedented proliferation of private educational institutions at all levels, which has culminated into cutthroat competition among education institutions [32]. Besides, Uganda's education landscape is increasingly becoming market-oriented and competitive in nature, hence the need for a more dynamic education entrepreneurship regime [20]. Thus, it is high time educational scholars, managers and policy makers appreciated the overdue wedlock between education and entrepreneurship. From a more academic perspective, there is need to stimulate more discourse in EE to create more awareness. Such discourse could also help to highlight key areas for potential investors in the industry [13].

However, as [23] observes, pessimistic voices towards adoption of entrepreneurship in education also ought to be listened to. Such voices have a potentially positive role to play towards EE, albeit a cautionary one. EE could easily get overboard; thus, it is helpful to warn educational entrepreneurs against their potential espousal of the profit motive at the expense of teaching and learning motives [26], [32]. To this end, pessimistic voices can be a valuable firewall (safeguard) that can protect education from illconceived EE initiatives [23].

Yet it is one thing for EE to be a commonly salvaging intervention in education management, and quite another for it to be feasible in a given a country, considering that country's legal framework and dominant school cultures. The next section shall therefore examine issues associated with the success of EE in the context of Uganda's educational landscape.

\section{FEASIBILITY OF EE IN UGANDAN EDUCATIONAL INSTITUTIONS}

Available literature indicates that educational institutions are generally characterised by resistance to change [23], which could militate against the success of EE. Such resistance to change is rooted in the many conservative rules and regulations typify the operational framework of many schools. "From the perspectives of school leaders, professionals, and parents, the ability to pursue innovation and change is largely blocked due to the proliferation of such regulations" [23]. However, literature also indicates that the success of EE in the short run is rarely a problem. The real problem is with sustainability of innovated changes over years and decades. Serious issues arise when it comes to the ability of schools not only to effect but-more so-to sustain change. There is something about schools that seems to stifle change, eventually returning to the previous way of functioning. Even new schools that start out with strong departures from existing practice seem to eventually move back towards the norm [23]. There are three explanations for this phenomenon, namely; traditional/conservative school cultures, schools as mutating agents, and the school as a conserving organisation [33], [23].

By "school culture" is meant educational stakeholders' widely shared conceptions and behaviour about the norms of how schools should function [23]. Available studies indicate that a traditional or conservative school culture abounds in many educational institutions [16], Ugandan schools inclusive. The culture is both restrictive (no individual initiatives taken without superior authorisation) and bureaucratic (too many levels of approval) [34]. It inhibits creativity, prevents new programs from being developed, and thus poses a challenge to EE [14]. This is so because to effect EE innovation is to suggest that certain schools' decade long traditions are to be reformed or even dropped altogether. Thus, although prior staff training is necessary in introducing EE, it can only be sufficient in ensuring cosmetic staff buy-in; otherwise usually there are more deeply rooted aspects of school culture that ought to be accorded more attention. "It is [staff] attitudes and routinised modes of operation that are the greatest obstacles to change, not a lack of skills" [23]. Part of the culture of many schools is bureaucracy, which is known for wearing down enterprising individuals to the extent of making them quit schools; for "they are frequently viewed as cynics, rebels, who do not conform to the standards set by the corporation [school]" [35].

The second explanation for lack of long term success of entrepreneurial innovation in education is that more often than not, schools are mutating agents of reform and not vice versa. "In fact, when reforms are forced on schools, the school often has more influence in modifying the reform than the reform has in modifying the school" [23]. This rationale is certainly related to that on school culture-schools are active communities united by deeply etched cultures that could resist the "invasion" of alien practices such as those necessarily implied by EE. "Much of the attempt to effect educational change and innovation has failed because of the ill fit between the reform and the extant culture of the school inducing the school to defuse the change attempt" [23]. 
The last explanation is that society does not as much seem to expect schools to play revolutionary roles as it expects them to play conservative ones [33], [23]. Schools are normally taken to be "conservative institutions charged with the primary goal of preparing the young to acclimate to and participate in the cultural, social, economic, and political life of an existing social entity" [23]. Usually it is society that changes schools, and not vice versa [33]. Change in school/educational practice is usually a response to some major turning point(s) ("disruptive" event/s) that is/are already alive in society. "Normally innovation is introduced to educational organisations by managers responding to external pressures" [23]. [33] concurs that EE may more easily succeed if pressure to go entrepreneurial originates from outside (schools), not from within. Otherwise, according to [33], with the exception of a few teachers, just a few administrators, and very few schools, everything is designed to bring change into the system from outside that system. This view however implies that, though exceptional, there are cases of successful-internally initiated-EE. Ugandan schools could learn from such cases.

Even then, a certain question remains unanswered: why do educational institutions usually resist change and/or innovation? One of the best overall answers is given by the new institutional theory [23]. The theory explains that,

The greater the dependence of an organisation on another organisation, the more it will become similar to them [sic]; the greater its dependency for resources on a given organisation, the more it will become isomorphic to that organisation; the less certain the relation between means and ends, the greater it will model itself after those organisations that appear to be successful [23].

For EE in Uganda, these hypotheses imply that unless society/social institutions on which schools depend (for learners, resources...) are the ones mounting pressure to schools to adopt certain entrepreneurial innovations, the innovations are not likely to succeed. If there are major changes in those external institutions (families, employing firms, teachers' unions, political forces...), the institutions will create pressure for a new isomorphism within schools [23].

No wonder then that major reforms in education usually coincide with significant changes in the social, political, and economic institutions that schools depend on for inputs.

Even those [authors] with more activist interpretations of school change accept the limits imposed by institutional theory. All of them acknowledge that this dependency is the main challenge to innovation in education and the success of the educational entrepreneur. [Otherwise] to ignore the forces that undermine long-term change in education is to repeat the futility that has characterised virtually thousands of well-intentioned attempts to alter education [23].

For Uganda, these views point to the need to appreciate the role of social movements in education for opening windows of opportunity for entrepreneurial change (See EE 3 in Figure 1). These might be social movements (pressure groups) such as PTAs (Parents' and Teachers' Associations), UNATU (Uganda National Teachers' Union) and UNAPSI (Uganda National Association of Private Schools and Institutions).

In another perspective, Uganda should learn also from the EE situation in other countries. In the US, it is reported that EE finds itself in serious dilemma [26]. Whereas authorities demand that school administrators and teachers be enterprising; the latter are labelled insubordinate or even selfish when they initiate creative ventures. This discourages creative teachers [33]. There is also demoralising organisational politics, as well as envy from peers [36]. Such realities have made some authors like [33] conclude that EE is impossible within the US setting: "In reality, the only way a truly entrepreneurial teacher can function is by leaving the system he or she wants to positively influence. It is not the teacher's fault. It is the system itself which has become so politicised and overly regulated that it is at fault" [33]. These views imply that even in Uganda, EE must be ready to face some certain and uncertain opposition, both from within and from outside educational institutions.

It is the European setting that offers Uganda some clearly successful EE cases. For example, in order to reorganise and reinvigorate her public schools, Sweden devised an entrepreneurial program known as "intraprenad", meaning "internal contracts" [34]. The contracts gave staff a high degree of autonomy to foster entrepreneurial practice in their departments and schools. The overall outcome was a more market- and output-oriented management perspective among staff. In addition, this innovation enabled schools both to retain their enterprising staff members and "to infuse intrapreneurship [EE] into the public sector" [34]. Uganda could take such an open/win-win approach.

For the case of private schools, although literature has often reported them to be more conducive for EE than public schools [34], this is not necessarily true for them all [14]. Only those schools that leave sufficient room for individual cross-functional teams, semi-autonomous venturing and experimenting can

Educational Entrepreneurship (EE): Delineating and Highlighting Its Domain ... (Genza Gyaviira Musoke) 
nurture an entrepreneurial culture [16]. As [37] contends, "social institutions that are run democratically and encourage independent thinking are more likely to produce individuals with entrepreneurial qualities than those with a less free atmosphere" (p. 46). [26] Advise might therefore also apply to Uganda; that for EE to succeed in any educational institution, be it private or public, there must be a significant change in the way such an institution is governed, organised, and administered. In a way, EE presupposes "a flat organisational structure with networking, teamwork, and mentors abounding, resulting in a cross-fertilisation of ideas" [14]. Otherwise, it remains true that "educational change [including EE] does not come easily" [23; prior adjustments have to be made - both to staff and parents' mind-sets and to managerial structure. These considerations are of paramount importance to educational administration and management in the Ugandan setting, in view of securing the success of EE.

\section{CONCLUSION}

The study makes the following conclusions. First, concerning the meaning of EE, the study defines $\mathrm{EE}$ as the innovative application of smart strategies to the management of education institutions in a fundamental way that can lead to the re-orientation and reorganization of a country's education system to suit society's changing (economic, social-cultural and political) needs in a sustainable manner. This definition transcends monetary rewards to include improvements in teaching-learning processes in view of better quality in education service delivery. The definition also considers EE as part of educational leadership in respect of the leadership qualities of pro-activeness, willingness to take risks, competitive aggressiveness, autonomy and strategic planning. In other words, the definition depicts entrepreneurial education managers as extraordinary leaders whose innovations or solutions to pressing school problems bring about transformative benefits to education service delivery.

Second, the scope of the EE domain comprises of four categories, namely: entrepreneurial activities and/or ventures that exclusively belong to the domain of teaching and learning such as innovative teaching approaches, remedial classes or teacher retooling programs (EE 1; Figure 1); profit-oriented supplemental businesses in the education sector such as transport, catering, cleaning services, publication of curriculum materials and/or provision of lab or ICT equipment to be paid for by schools (EE 2; Figure 1); socioeducational ventures, which focus on developing new answers to current social and/or ecological challenges in/through schools for the enhancement of social values such as providing school-going children with subsidised mid-day meals (EE 3; Figure 1); and, finally, entrepreneurial activities that simultaneously cut across the three domains above such as a profitable business intervention devised in support of an educational initiative for socially disadvantaged children (EE 4; Figure 1).

Thirdly, on the significance of EE in Uganda today, EE is capable of igniting educational managers to think and act beyond compliance with current rules and resources, institutional demands and accountability regimes to adopt a proactive role in advancing initiatives to create new educational organisations and execute new educational visions. Besides, such entrepreneurial oriented educators will be able to cope and lead more effectively in the current dynamic educational environment characterized by: a highly liberalized, privatized and marketised education sector; a growing public dissatisfaction with the quality of teaching and learning in schools; rising stakeholder demand for accountability amidst dwindling public resources for education; and the growing need for educational networking and strategic alliances with both educational and non-educational audiences. Entrepreneurial competencies acquired by educational administrators and managers alike can enable them to adopt a corporate approach to school management, by introducing educational resource mobilization competencies needed to provide quality education in quantity.

Finally, although available literature shows that the fortunes of EE may render it an irresistible initiative at both institutional and national levels, its success in the Ugandan context should not be taken for granted due to the following considerations: educational institutions are generally characterised by resistance to change; challenge of sustainability of innovated changes in the long run; existence of a restrictive and bureaucratic school culture that can easily inhibit creativity or prevent new programs from being developed; the propensity of schools as mutating agents of reform other than the other way round; and, lastly, the limited expectation of society for schools to play a revolutionary role in nation building. Combined, these factors can militate against the success of EE. Even then, smart edupreneurs could network with wider groups both within and outside schools to garner support, and thus outwit several of these challenges.

\section{RECOMMENDATIONS}

a. There is need for educational scholars, managers and policy makers to appreciate the overdue wedlock between education and entrepreneurship. From a more academic perspective, there is need to stimulate more discourse on EE to create more awareness. Such discourse will also help to highlight key areas for potential investors in the education industry. 
b. Need to sensitize key stakeholders such as families, employing firms, teachers' unions and political forces about the importance of EE in stimulating society (on which schools depend for learners and resources) to mount pressure on schools to adopt certain entrepreneurial strategies in their education service delivery.

c. As regards the feasibility of EE in Uganda, pessimistic voices towards adoption of entrepreneurship in education should be taken seriously but objectively. Otherwise, a hasty implementation of EE could be counterproductive in at least two ways: First, edupreneurs' potential espousal of the profit motive at the expense of teaching and learning could put the realisation of national educational goals in jeopardy. Secondly, it might rub overriding school cultures, societal expectations of the school and existing regulatory frameworks on the wrong side, hence arousing undue opposition.

d. For EE to succeed in both public and private educational institutions, there is need for a significant change in the way these institutions are both organised and administered. Given that EE presupposes a more flat organisational structure with networking, teamwork, and mentors that result in a crossfertilisation of ideas; there is need for prior adjustments both to staff mind-set and managerial structures.

\section{REFERENCES}

[1] Attali, M. O. and Yemini, M. (2016). Initiating consensus: stakeholders define entrepreneurship in education. http://www.tandfonline.com/doi/full/10.1080/00131911.2016. 1153457? 2nd-11-2016.

[2] TISSA (2013). Teacher Issues in Uganda: A Shared Vision for an Effective Teachers Policy. UNESCO.

[3] Kahavizakiriza, R., Kisiangani, B. W. and Wanyonyikukubo, D. (2015). Financial management in public secondary schools in Kenya: A case study of Lurambi Sub-County, Kakamega County. In International Journal of Scientific and Technology Research, Vol. 4, Issue 09, pp. 167-178 www.ijstr.org [Accessed on 4 ${ }^{\text {th }}$ April, 2017]

[4] Noguchi, J. (2006): The science review article - An opportune genre in the construction of science. Linguistic Insights Volume 17. Bern: Peter Lang.

[5] Ridley, D. (2008): The literature review - a step-by-step guide for students. London: Sage Publications.

[6] Mayer, P. (2009). Guidelines for writing a Review Article. http://www.plantscience.ethz.ch/ education/Masters/courses/Scientific Writing. Zurich: Uni Basel.

[7] Kombo, K. D. and Tromp, L. A. D. (2006). Proposal and thesis writing: an introduction. Nairobi: Pauline Publications Africa.

[8] NCERT (2014). Basics in education: Textbook for B.Ed. Course. New Delhi: National Council of Educational Research and Training.

[9] Nkata, J.L. (2005). Emerging issues in education management in developing countries in the 21st century. Kampala: Mashah Publishers Ltd.

[10] UNESCO (2013). Glossary of Curriculum Terminology. Geneva: UNESCO-IBE

[11] Arends, R. I., Winitzky, N.E. and Tannenbaum, M.D. (1998). Exploring teaching. New York: McGraw

[12] Owolabi, S.O. (1987). Political and cultural context of educational planning. Ibadan: Aderibigbe.

[13] Kourilsky, M. L. \& Hentschke, G. (2003). Educational entrepreneurship and covisionary multisectorism. In Kourilsky, M. L. and Walstad, W. B. (Eds). Social entrepreneurship. Dublin: Senate Hall Academic Publishing; pp. 115-139.

[14] Hisrich, R. D., Peters, M. P. and Shepherd, D. A. (2005). Entrepreneurship (6 ${ }^{\text {th }}$ ed.). Boston: McGraw-Hill Irwin.

[15] Busnov, M. (2014). Individual-level determinants of intrapreneurship in the Netherlands. http://www.google.com/url?sa=t\&rct=j\&q=\&esrc=s\&source=web\&cd=1\&cad=rja\&uact=8\&ved=0CB0QFjAA\&url

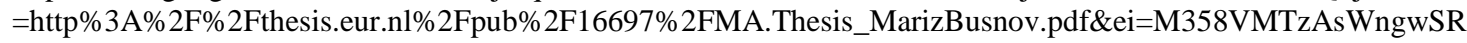
14QY\&usg=AFQjCNHgnnc0QKgirdwPanESvLBuWm8q5w\&sig2=Vhh2BwNrr0wKITIXOV9kkg\&bvm=bv.80642 063,d.bGQ [Accessed $1^{\text {st }}$ December 2014]

[16] Serinkan, C., Kaymakci, K., Arat, G. and Avcik, C. (2013). An Empirical Study on Intrapreneurship: In A Service Sector in Turkey. 2nd Cyprus International Conference on Educational Research, (CY-ICER 2013).http://www.academia.edu/7368190/An_EmpiricalStudy_on_Intrapreneur ship [Accessed 16th October 2014].

[17] De Jong, J. P. J., Parkerii, S. K., Wennekersiii, S. and Wuiv, C. (2011). Corporate entrepreneurship at the individual level: measurement and determinants. Bredewater: SCALES.

[18] Yemini, M., Addi-Raccah, A. and Katarivas, K. (2014). I have a dream: school principals as entrepreneurs. In: Educational Management Administration \& Leadership, pp. 1-15.

[19] Bostjan, A. and Hisrich, R. D. (2001). Intrapreneurship: construct refinement and cross-cultural validation. Journal of Business Venturing 16, 495-527

[20] Man, T. W. Y. (2010). Clarifying the domain of educational entrepreneurship: Implications for studying leadership, innovation and change. Unpublished paper; Hong Kong Institute of Education.

[21] Smith, K. and Petersen, J. L. (2006). What Is Educational Entrepreneurship? In Hess, F.M. (Ed.): Educational Entrepreneurship: Realities, Challenges, Possibilities, Harvard Education Press

[22] Webber, C. and Scott, S. (2008). Entrepreneurship and Educational Leadership Development: Canadian and Australian Perspectives, 12(14). IEJLL: International Electronic Journal for Leadership in Learning, Vol. 12. http://iejll.journalhosting.ucalgary.ca/iejll/index.php/ijll/article /view/558/220 14th November 2016.

[23] Levin H. M. (2006). Why is educational entrepreneurship so difficult? In Hess, F.(ed.): Educational Entrepreneurship. Cambridge, MA: Harvard Education Press. 
[24] Pihie, Z. A., Asimiran, S. and Bagheri, A. (2014). Entrepreneurial leadership practices and school innovativeness. South African Journal of Education; 2014; 34(1), pp. 1-11

[25] Owolabi, J. (2005). Policy-making and educational policy analysis. Kampala: Makerere University.

[26] Lavaroni, C. W. and Leisey, D. E., 2014. Bringing the Excitement of Entrepreneurism to the Public Schools http://www.edentrepreneurs.org/edupreneur.php [Accessed18th October 2014].

[27] Kurian, G. T. (2013). The AMA dictionary of business and management. New York: AMACOM.

[28] Mulder, M., T. Weigel \& K. Collins (2006). The concept of competence concept in the development of vocational education and training in selected EU member states: A critical analysis. Journal of Vocational Education and Training, 59,1, 65-85.

[29] Lanny, V. (2008). Differentiating Competence, Capability and Capacity. Innovating Perspectives; Vol. 16, No. 3, pp. $1-2$.

[30] Cencič, M.\& Štemberger, T. (2015). Entrepreneurial competences for school leadership teams (EC4SLT). www.google.com/url?sa=t\&rct=j\&q=\&esrc=s\&source=web\&cd=1\&ved=0ahUKEwjckNHusJnQAhUGmZQKHaJ9 D84QFggaMAA\&url=http\%3A\%2F\%2Fwww.ec4slt.com\%2Fdocuments\% $10^{\text {th }}-9-2016$.

[31] Genza, G. M. \& Muwagga, A. M. (2014). Human and economic development implications of selected knowledgemediation practices prevalent among secondary school teachers in central Uganda. Journal of Development Studies (UMU, Nkozi) 1(4) (2014), pp. 69 - 88.

[32] Musisi, B. (2013). Pedagogical ramifications of the competitive secondary schools. PhD Dissertation: Makerere University.

[33] Lavaroni, C. (2014). The creative teacher and the intrapreneurial process. http://www. edentrepreneurs.org/paper.php [Accessed16th October 2014].

[34] Westerberg, M., Nilsson, K. and Fältholm, Y. (2011). Using internal contracts to promote intrapreneurship in the public school system: hopeless half-measure or promising hybrid? The 56th Annual ICSB World Conference (paper). https://pure.ltu.se /portal/en/ publications/using-internal-contracts-to-promote-intrapreneurship-in-thepublic-school-system\%28cca975b0-88f8-48ad-ba20-870ba547316c\%29.html [Accessed on 20th October 2014].

[35] Kirby, D. A. (2003). Entrepreneurship. London: McGraw Hill Education.

[36] Teltumbde, A. (2006). Entrepreneurs and Intrapreneurs in Corporations. In Vikalpa, Vol. 31: January-March, pp. 129-132.

[37] Nansubuga, K. (2003). The impact of entrepreneurs' behaviour on the small scale business particularly in the foods and beverage industry: case study of Owino and Ntinda Markets, Kampala District. Dissertation, Uganda Martyrs University. 